\title{
Resenha: \\ Dimensões antropológicas de gênero e reprodução: do ponto de vista de uma mulher em Maputo ${ }^{1}$
}

Alexandre Aparecido dos Santos ${ }^{2}$

Rosangela da Silva ${ }^{3}$

PONDJA, Clélia Francelina Ozias. A Mulher em Maputo: Dimensões Antropológicas de Género e Reprodução. Moçambique: Real Design, 2018.

\section{Introdução}

A obra "A mulher em Maputo: Dimensões antropológicas de gênero e reprodução", escrita por Clélia Francelina Ozias Pondja ${ }^{4}$, discute, de um ponto de vista antropológico, a questão de gênero e reprodução em Moçambique, mais especificamente nos distritos de KaMpfumo e KaTembe localizados na cidade de Maputo, entre os anos de 2012 a 2015. A relevância e autoridade de seu estudo se dá, primeiro, devido ao fato de sua abordagem ter se centrado nos aspectos socioculturais que influenciam a saúde reprodutiva, destacando-se dentre várias outras abordagens centradas nos elementos biológicos do corpo da mulher. $\mathrm{E}$ segundo, de forma preponderante, por ser mulher, moçambicana e doutora em antropologia pelo instituto universitário de Lisboa em Portugal.

A elaboração desta resenha exigiu muito afinco devido à extensão e à complexidade da obra. No entanto, foi também muito prazerosa, pois, para além da relevância da discussão, a sua organicidade consiste em uma produção intelectual de alto nível didático. Neste sentido, utilizar-nos-emos dos caminhos traçados pela própria autora para dar o norte dos elementos centrais que serão retomados neste trabalho de apresentação da referida obra.

Como frisado pela autora, a obra se divide em três partes que se inter-relacionam, a primeira intitulada "Estado da Arte"; a segunda "A bistória da Saúde Materno-Infantil em Moçambique"; e a terceira: "O Estudo de Caso". As discussões empreendidas em cada uma dessas partes têm por objetivo:

\footnotetext{
O presente trabalho foi realizado com apoio da Coordenação de Aperfeiçoamento de Pessoal de Nível Superior - Brasil (CAPES) - Código de Financiamento 001.

2 Doutorando no Programa de Pós-Graduação em Ciências Sociais. Faculdade de Ciências e Letras, Araraquara (Unesp). Bolsista Capes DS. alexandre.sociais@hotmail.com.

3 Doutoranda no Programa de Pós-Graduação em Ciências Sociais. Faculdade de Ciências e Letras, Araraquara (Unesp). Bolsista Capes DS. ro.toledo84@hotmail.com.

4 Doutora em Antropologia pelo ISCTE-IUL/Instituto Universitário de Lisboa (2017). Investigadora do Centro de Estudos Internacionais (CEI) ISCTE-IUL em Lisboa/Portugal. Consultora de Programa no projeto IMPACT/BICA no Centro de Integridade Pública (CIP) - Moçambique.
} 
a) analisar o problema de pesquisa apresentado, que se refere aos aspectos socioculturais ligados à saúde reprodutiva, dando ênfase à subjetividade da mulher em relação a sua experiência frente a esta questão;

b) dar respostas a três questões gerais elencadas pela autora, que são: "como se configura a saúde reprodutiva em Maputo na atualidade?" " como se configura a relação da mulher/mãe com os sistemas de saúde biomédico e tradicional?" e "quais as expectativas que a sociedade como um todo constrói entorno da "condição" da maternidade?" (PONDJA, 2018, p. 28).

c) toda a análise ocorre por meio da utilização de duas abordagens metodológicas: a primeira pautada em uma análise quantitativa que parte do macro para o micro, na qual a autora faz uma pesquisa que procura resgatar a história da implementação das Políticas de Saúde Pública em Moçambique; e a segunda baseada em uma pesquisa de campo, observação participante, focada nas práticas e ponto de vista dos profissionais de saúde vinculados à biomedicina e às práticas de cura vinculadas ao saber popular/ tradicional. E verificar também a importância dada e quais são os potenciais benefícios ao participar destes diferentes sistemas de saúde na percepção dos “utentes”, designados por ela como mulheres-mães e homens-pais.

\section{O estado da arte}

A primeira parte da obra se constitui em uma revisão da literatura que consolida a base para as subsequentes discussões acerca das representações sobre a experiência reprodutiva das mulheres em Maputo. De maneira geral, a autora retoma a historicidade das discussões produzidas acerca da categoria gênero e da sua importância nos estudos sobre as mulheres no sentido de questionar o papel de subalternidade atribuído a elas na sociedade patriarcal.

Esta discussão é nodal, posto que a sociedade moçambicana se constitui sob essas mesmas bases, portanto, reproduzindo esta relação entre os gêneros, a qual deixa evidente a condição de opressão vivida pelas mulheres. Um exemplo desta afirmação é a relação entre as escolhas individuas e as pressões situacionais, isto é, o fato de que em Moçambique a única sexualidade aceita para a mulher é a que resulta na reprodução (a mulher-mãe goza de estatuto privilegiado).

Outra questão que tem sua historicidade recuperada é a noção de saúde e doença construída em nossa sociedade. A autora apresenta uma crítica ao modelo biomédico atual que se fundamenta na perspectiva individualista e no biologismo de visão dualista que separa corpo e mente; natureza e cultura; indivíduo e sociedade. E que, primordialmente, constitui-se em uma forma de saber que subjuga as demais.

\section{A história da Saúde Materno-Infantil em Moçambique}

A segunda parte da obra traz relevantes informações geográficas, econômicas, sociais e culturais de Moçambique, assim como contextualiza as bases sob as quais se construiu, e ainda está pautada, a saúde reprodutiva deste país que possui altos índices de mortalidade materna e neonatal. 
É importante ressaltar que o conceito de saúde reprodutiva abarca certos direitos humanos que estão embasados tanto por leis nacionais quanto por documentos internacionais. Nesse sentido, para abordar a realidade da saúde reprodutiva dos distritos de KaMpfumo e KaTembe, a autora faz um paralelo de como tal questão tem sido abordada em Moçambique, e, em alguns momentos, traz para a análise o contexto do continente africano como um todo, justamente para evidenciar como há um entrelaçamento de tais ações com políticas mais amplas de âmbito internacional.

Pondja retoma a história do serviço de saúde no período de 1920 a 1974 em Moçambique. Para a autora, as inciativas de cunho internacional se configuravam como justificativa para a continuidade do processo de colonização e, por consequência, a continuidade da dominação dos portugueses sobre Moçambique.

No que tange ao atendimento de saúde das crianças e das mulheres, isso ocorria apenas quando tinham vínculos com aos militares. Mas, embora a implementação dessas políticas tenha se desenvolvido a partir deste atendimento segmentado e hierarquizado, elas trouxeram alterações no que diz respeito às noções que esta população tinha acerca da doença e saúde, assim como também sobre as formas de tratamentos.

A Conferência Internacional do Cairo, ocorrida em 1994, que se propôs a discutir população e desenvolvimento, partia da premissa de que era necessário promover a melhoria da saúde sexual e reprodutiva. Para tanto, elencou-se também fatores que impedem a sua efetivação, como: falta de conhecimento sobre a sexualidade e dificuldade de acesso aos serviços de saúde reprodutiva; a pobreza e a discriminação de gênero.

No entanto, a biomedicina não consegue dar conta de atender a todos, de forma que as práticas tradicionais (de mais fácil acesso) continuaram presentes no cotidiano moçambicano. Porém, com o processo de independência ocorrido em 1975, o partido que assume propõe alterações na política administrativa no sentido de eliminar os resquícios coloniais e tradicionais, o que resultou em uma intensa perseguição aos sujeitos praticantes da medicina tradicional, vista como obscurantismo (PONDJA, 2018).

Pondja retoma discussões - com base nas obras: Tradição, Pessoa, Género e DST/HIVI AIDS no Sul de Moçambique de Henrique Passador (2009); e Género Cuidados Consigo Mesma: Sexualidade e Erotismo na Provincia de Tete, Moçambique, Sexualidade e Práticas Vaginais das autoras Brigitte Bagnol e Esmeralda Mariano (2008-201) - sobre práticas e noções acerca da sexualidade.

É importante frisar que a perspectiva de Pondja vai ao encontro das proposições dos autores citados acima ao lançar o olhar sobre a sexualidade como uma construção social, destacando o fato de que cada cultura elabora suas próprias concepções. Um bom exemplo disso são as "práticas vaginais", ainda presentes em diferentes regiões da África, que resultam no alongamento dos pequenos lábios da vagina e que são consideradas pela Organização Mundial da Saúde (OMS) como uma mutilação feminina.

A sexualidade ocupa, portanto, um importante papel para a formação da identidade e na definição dos papéis sociais do que é visto como feminino e masculino. Em Maputo, essas demarcações se dão desde a infância, momento em que as meninas e meninos são direcionados para atividades específicas. 


\section{O Estudo de Caso}

$\mathrm{Na}$ terceira e última parte, Pondja apresenta os resultados de sua pesquisa. Inicia pontuando que os distritos de KaMpfumo e KaTembe não eram objetos da pesquisa no seu projeto originário e sim Chockwè e Ribaúe, localizados na Zona Sul e na zona Norte de Moçambique. No entanto, diante do atraso dos recursos advindos da bolsa de estudo - acontecimento a que ela se refere no texto como uma situação de "constrangimento" que iria financiar a pesquisa, ela se viu diante da necessidade de repensar o campo tendo como elemento determinante o menor dispêndio econômico. Como resultado desta contingência, foram escolhidos os dois distritos que possuem proximidade geográfica, o que ocasionou também uma alteração no título da obra de "A mulher em Moçambique..." para a "Mulher em Maputo...".

Embora localizados em uma mesma região, tais distritos possuem uma grande heterogeneidade. KaMpfumo possui características urbanas e KaTembe características rurais, acrescenta-se a isso uma acentuada diferença em relação às questões demográficas, de acesso a bens e serviços públicos e, de maneira geral, socioculturais.

A abordagem metodológica adotada pela autora - embora contenha uma apurada pesquisa quantitativa presente na segunda parte da obra - está centrada nas abordagens qualitativas de cunho etnográfico. No seu primeiro contato com os interlocutores, a autora utilizou um questionário exploratório para caracterizar seu problema, o que deu base para a elaboração de entrevistas semiestruturadas e abertas, concluindo a pesquisa com a observação participante que se centrou na análise: a) das ações dos profissionais do sistema convencional "(o médico ginecologista obstetra, enfermeira SMI, enfermeira parteira)" e do sistema tradicional "(a curandeira, a parteira tradicional e o vendedor de medicamentos tradicionais)"; b) e nas narrativas e trajetória das mães/utentes.

O universo da pesquisa corresponde a 36 entrevistados. Dentre eles, 20 mulheres/mães, dez de cada distrito, a escolha delas se deu a partir de cinco critérios: estar em idade reprodutiva (dos 15-49 anos); residir nos distritos que constituíam objeto da pesquisa; falar português; ter sido mãe no período de até cinco anos atrás ou estar grávida; aceitar fazer parte da pesquisa. O contato com as primeiras entrevistadas ocorreu via redes sociais da pesquisadora, dos seus familiares e amigos, e, posteriormente, essas iam indicando outras mulheres, método identificado no trabalho como "bola de neve".

Fizeram parte da pesquisa também 10 homens parceiros, tendo como critério de inserção a aceitação prévia de sua companheira. Os 6 últimos participantes eram profissionais da saúde, divididos da seguinte maneira, entre o sistema de saúde convencional e o tradicional: um médico ginecologista/obstetra; uma enfermeira de saúde materna infantil; uma parteira elementar; uma parteira tradicional; uma curandeira; e um vendedor de medicamentos tradicionais.

A partir da análise de como se dá o acesso ou não ao atendimento ao pré-natal e a assistência ao parto oferecidos pelo Sistema Nacional de Saúde (SNS) (a medicina convencional) suas pesquisas exploratórias a levaram a identificar o grupo de risco. Há apenas um Centro de Saúde (CS) em cada distrito, um deles oferece apenas o atendimento pré e pós-natal, o 
outro oferece também o serviço do parto assistido, porém apenas o natural, haja vista que a enfermeira parteira não está habilitada para o parto cirúrgico.

Para além deste atendimento parcial que estes centros oferecem, as entrevistadas se queixaram do longo período de espera para o atendimento, da existência de práticas clientelistas que priorizam algumas mulheres em detrimento de outras, além dos maus tratos verbais no atendimento por parte dos profissionais (grosserias e ofensas morais).

Uma das enfermeiras entrevistadas concorda que existem sérios problemas no atendimento referente à falta de recursos humanos. Esses fatores dificultam o acesso ou até mesmo causam a desistência diante de tais serviços. Pondja acompanhou um parto em um dos CSs, ela indica que o parto realizado está ainda muito longe do que determinam as legislações atuais sobre o parto humanizado, o qual propõe uma alteração na relação médico-paciente, em que a gestante pode escolher, por exemplo, a posição mais confortável para o parto e contar com a presença do pai da criança ou de outro familiar.

A enfermeira que Pondja acompanhou afirma que é o profissional da saúde que determina como deve ocorrer o processo, pois é ele que detém o conhecimento. A pesquisadora comenta que, diante dessa falta de sensibilidade, que gera uma situação de insegurança e medo, muitas mulheres têm procurado o sistema de saúde privado, o qual respeita mais as suas escolhas para a realização do parto natural, assim como também são mais suscetíveis para a realização do parto cirúrgico (cesariana).

O acesso à medicina tradicional é de mais fácil acesso e é sobre ele que as entrevistadas possuem maior conhecimento. Além disso, seus agentes (curandeiras, parteiras tradicionais, vendedores de remédios, pastores/profetas) são reconhecidos e certificados por órgãos oficiais, como a AMETRAMO (Associação Moçambicana de Médicos Tradicionais) e o MISAU (Ministério da Saúde), e detêm o respeito da população, que acredita na sua capacidade de cura que vai além de moléstias físicas, englobando também a cura espiritual.

Mas, na prática, qual dos dois sistemas, que representam diferentes representações acerca da construção da noção de saúde e doença, assim como da gravidez e do parto, as mulheres que vivenciaram ou estão vivenciando a experiência reprodutiva em Maputo acessam? As conclusões a que chegou Pondja em seu estudo, o qual se deu tanto nos espaços públicos quanto no ambiente privado, é que há um hibridismo resultante da interação terapêutica.

Um dado importante refere-se à idade que a maioria das mulheres tivera sua primeira gravidez, uma vez que a experiência da gravidez possui a dimensão de, ao gerar um filho, vivenciar a experiência do processo de transformação de moça para mulher. O papel social de mãe acarreta uma série de novas obrigações sociais e uma nova relação com o corpo que inclui proibições, como: o tipo de roupa que deve vestir, os lugares os quais frequentar, os comportamentos a serem adotados. Existe um papel social idealizado acerca da maternidade, alicerçado na noção de "boa mãe" que vai direcionar a mulher a práticas específicas da concepção do filho, do parto e ao pós-parto. Tanto entre os homens quanto entre as mulheres é muito presente os discursos acerca da predisposição natural para a maternidade, a mãe como "guardiã" da criança. 
Por um lado, há o que os médicos recomendam, no sistema convencional, acerca da necessidade de realizar o pré-natal que se dá a partir do terceiro mês (a grande maioria das mulheres só tem contato com o médico ginecologista neste período, portanto, após a gravidez). Os primeiros cuidados referem-se à realização de exames para detecção de HIV e malária, que são as causas mais diretas que levam ao óbito materno e neonatal, assim como também para identificar e encaminhar para os hospitais as pacientes de alto risco, que são as mulheres que já fizeram cesariana; anêmicas, hipertensas; com idade de 16 anos ou menos e as menores de $1,50 \mathrm{~m}$.

Por outro, no sistema tradicional, as principais "perturbações" indicadas por estes agentes são as cólicas menstruais, corrimento e verrugas (HPV - Papilomavírus Humano) vistos como naturais, mas que precisam ser tratados para garantir a continuidade da gravidez, popularmente conhecido como "amarrar a barriga". Há toda uma dimensão simbólica envolvida nestes tratamentos, com remédios naturais de plantas, óleos de origem animal, rezas e rituais.

A pesquisa apresenta informações acerca de algumas destas práticas e processos de cura ou rituais para evitar enfermidades que incluíam proibições de certos alimentos, do sexo depois do sexto mês de gestação, para não participar de cerimônias fúnebres, de ocultar a gravidez até o terceiro mês, de não fazer o enxoval e nem escolher seu nome antes do nascimento, de resguardar o bebê apenas ao convívio doméstico nos primeiros seis meses ou até cair o umbigo (práticas estas mais presente entre as mulheres de menor instrução, 35\% delas).

Embora um percentual alto, 90\% das mulheres, tenha dado à luz pelo menos uma vez na maternidade com parto realizado por médico ou parteiras (em sua maioria partos normais, embora as cesarianas tenham aumentado), na periferia e no campo ainda $46 \%$ dos partos ocorrem fora das US (Unidades Sanitárias) - a maioria devido à distância em relação às US, dificuldade no acesso ao transporte ou por questão econômica.

A pesquisa demonstrou também que as mulheres têm mais conhecimento acerca da diversidade dos métodos contraceptivos do que seus parceiros, predominando a utilização da pílula, do DIU e do preservativo masculino (embora o uso deste não seja bem visto nas relações estáveis). Esses diferenciais acerca dos conhecimentos dos métodos entre homens e mulher acabam por resultar no fato de que recai sobre a mulher a escolha do método, bem como a continuidade ou não do seu uso. 


\section{Considerações finais}

Para finalizar, Pondja apresenta suas principais conclusões e indica as possíveis contribuições de sua pesquisa para a melhoria das condições das Políticas Públicas para a saúde materna e infantil de Moçambique. Em sua perspectiva, para além de identificar o hibridismo no acesso aos diferentes sistemas de cura, é preciso fazer o seguinte questionamento: quando se dá o acesso a um ou a outro sistema?

O acesso ao sistema biomédico ocorre de maneira mais recorrente no momento do parto, no monitoramento do crescimento da criança e na obtenção dos métodos contraceptivos. Já os saberes tradicionais são mais acionados diante da ameaça de aborto e quando o trabalho de parto se arrasta, vistos como momentos em que a medicina convencional não dá conta do processo de cura, pois ela está relacionada ao mundo físico e, também, ao espiritual.

A relevância da utilização da abordagem antropológica feita pela autora, que, para dar conta de seu objeto, valeu-se de métodos quantitativos e qualitativos, está localizada justamente na capacidade de poder ter evidenciado como esses dois sistemas de saúde acessados por estas mulheres representam duas cosmologias de saberes terapêuticos diferentes. Assim, a partir deles, elas construíram suas percepções e representações acerca da maternidade e do seu corpo - e isso independe (em certo nível) do acesso ou não à escolaridade - e seu contributo reside justamente no fato de demonstrar que o referido hibridismo terapêutico deve ser considerado para melhorar o atendimento neste âmbito. 